\title{
Teaching the Alphabet: Reconciling the Past and the Present
}

\author{
Linda Shidler - Tara Harrigan
}

Published online: 20 November 2009

(C) Springer Science+Business Media, LLC 2009

\begin{abstract}
This guest editorial focuses on a reflective journey of two early childhood professionals as student and teacher turning into classroom teacher and literacy coach. In addition, this editorial explores some of the worries the classroom teacher expressed during a reflective journey in learning ways in which to teach alphabet letter recognition that increased child outcomes.
\end{abstract}

Keywords Alphabet learning - Early childhood literacy . Teacher education

Throughout my career I have found that, when working with teachers, their instructional practices can become stagnant due to the "what I shouldn't dos", especially when thinking through how to help children begin their journey into literacy. As a teacher educator since the 1990s, I talked about the "shouldn't dos" when teaching the alphabet. As a student in my class, Tara was cautioned as well. Professional development for early childhood education teachers, in the 1990s primarily used the premise of whole language to discuss teaching alphabet letters and discussed the indirect methods of instruction, using maturation or "child readiness" as guiding forces. Ten plus years later, Tara and I met again, this time with Tara as a classroom teacher and me as her literacy coach.

L. Shidler $(\square)$

Nova Southeastern University Mailman Segal Institute Tampa, 3631 Queen Palm Drive, Tampa, FL 33619, USA

e-mail: shidler@nova.edu

T. Harrigan

Hillsborough County Schools, Egypt Lake Elementary, 6707 North Glen Avenue, Tampa, FL 33614, USA
The "shouldn't do thinking" that dominated both Tara's and my beliefs about teaching the alphabet in the 1990s most often centered around staying away from teaching and/or assigning time frames for studying independent alphabet letters. Tara recalled of her past practices:

"[I]...worried about teaching such an isolated skill in such a direct way" and "[I thought] concentrating on specific letters was seen as out-of-date, and unsuccessful".

As the political and educational climate changed, largely due to the findings of the National Reading Panel, early childhood education was once again deemed essential in preparing children for school success. Teachers were charged with delivering intensive early literacy programs in which direct instruction of alphabet letter recognition was a key component. Early childhood educators were urged to take note of the evidence, as it started to accumulate, of the number of letters children were able to recognize as they entered kindergarten. Alphabet recognition played a direct role in the children's ability to acquire the basic skills necessary to achieve academic success. As Tara's literacy coach I reviewed this information with Tara and she begun to reconsider and redesign her approach to teaching the alphabet stating:

"...the most difficult part of making the change was to realize it was okay to make a change. I realized that unlike how I understood the past practices of teaching specific letters at the exclusion of others, I was using all the letters and spending focused time on specific letter".

But Tara was still concerned that children would in some way feel pressured to recall letter names and would lose some momentum in the rest of their development or 
would begin to see preschool as a task, losing a love of learning at a crucial time.

“...originally I did worry about the effects on the children of this more direct approach to teaching isolated skills. But I saw the children did not notice the difference in the instruction; they feel successful when they master a skill without the regard to the approach I used to help them to that point. The children have even become peer teachers as they can assist another child in identifying alphabet letters!”.

Parent/family involvement also became more focused with our approach. We knew parents wanted to help. Parents want their children to learn! We found that helping our students often consisted of the children themselves engaging parents and families in their early literacy learning. We started with the knowledge that every parent can identify the 26 letters of the alphabet. This is a skill that they know how to pass on. Through this skill, teachers can expand parents' knowledge base in how to help their children in other literacy skill development. So as classroom teachers we need to start simple...help parents remember to teach alphabet letter identification. As children point out letters to their parents, alliteration, letter sounds, and rhyming will follow. In Tara's classroom she recalled:

"...Parents interacted with their children and the letters because as a class we formed a habit of identifying them each time we entered and exited the classroom. Parents would see their children doing this and then engage in conversation with them or assist them with unknown letters. We also sent home notes on the progress the children were making about once a week so parents could constantly have access to updated information regarding their children's progress. We ask them for help in identifying alphabet letters and teaching their children about print. I was also cognizant of thanking them, a simple note saying, 'with your help, Daniel learned 5 more letters' goes a long way".
It is time for us as early childhood educators to come together and advocate practices which offer children the BEST possible start. We should refrain from condemning practices by using emotionally-laden terms like "drill and kill" and "flashcards" but rather look to see what value can be taken from each practice based solely on child outcomes. No single method can accomplish all that we want for children. When asked to describe her classroom practices in 2009, Tara responded:

“...I do not feel that any of the labels of current approaches fit what I am doing in the classroom as I don't use a SINGLE method of teaching. I combine techniques to achieve the best possible environment for the children. Some of the techniques are from Whole Language and some are more in-line with Direct Instruction. I make time for the children to investigate and interact independently and I facilitate or lead their exploration. I think what I practice can be labeled as "best practices". I want what is BEST for the children and I want them to have every opportunity to accomplish what is expected of them and beyond. That may mean I have to learn new practices or even embrace what was once thought of as old. But my job is to reach all the children. I have not given up my past practices, I have instead supplemented them with additional practices. I stopped worrying about what I 'shouldn't do' and focused on how to teach all the children".

The goals of early childhood education, specifically preschool, should include helping children start Kindergarten with the skills they need to succeed. Using appropriate methods in preschool education needs to be defined by the desired outcomes and the children's abilities. Teachers and parents/families can do so much for young children and their future school success. It is time to put away the "shouldn't do" thinking and become focused on helping children start their journey into literacy with the most solid foundations we can help to build. 